\title{
Fractional Banking System with the Unknown Risk (see verses)
}

\author{
Jilani Ben Touhami Meftah¹ \\ ${ }^{1}$ APIUM University of Malaya \\ Email:meftah@gmail.com
}

\begin{abstract}
The fractional banking system to day is the basis banking transactions, it is the engine of economic processes in the global banking and the seed that grew out of the economies around the globe and the main factor attributed to the successes of the global economy and its failures. Perhaps the most important reasons for this neglect is the adoption of thought Islamic Economics contemporary, and the seriousness of this matter is fractional banking is some of the descriptions on the origins of the law and rules.
\end{abstract}

Keyword: fractional banking system; banking transactions

أولا : الصفة القمارية، نظرا لطبعية الفلسفة الاحتمالية القمارية التي يقوم عليها هذا النظام والطبيعة السحرية التي يغرر بها رواده بما يعدهم به من سرعة الربح الوفير لمن سيصادفه الجظظ منهم جعلته فوق كلّ مساءلة نظرا لما يتمع به من خصانة قانونية أضفته عليها عصابات القمار والاستغلال المصرفي. وَنَنْتُنَا لهاذ النظام بالقمار لاشتراكه مع القمار في الأساس والنتائج: فالأساس الاحتمالي الذي تقوم عليه كل عمليتين ـ القمار

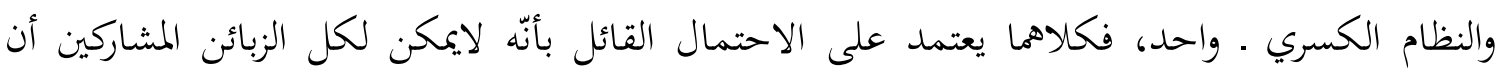
يسترجعوا بحتمعين فردا فردا ما دفعوه مرة واحدة، بل الاحتمال الأقرب لديهما هو استرجاع المشاركين بعض المدفوع في فترات متعاقبة والفائض يبقى لصاحب لعبة القمار أو لصاحب لعبة القمار أو صاحب النظام الكسري. أما النتائج فهي الربج المضمون لكليهما والخسارة المؤكدة لزبائهما. فصاحب محل القمار رابح في كلّ حالاته، فاحتمالية الربح عنده قد تصل إلى 99\% أي أن يشارك مثل في عملية القمار 100 شخص بمقداره دولار من كل مشارك بملغ إجمالي قدره 10000 دولار، وفق احتمالية الفوز لهم هجتمعين بنسبة 10 إلى 10\% فقط أي أنّ واحد إلى عشرة منهم فقط يمكن أن يصادفه الحظ باسترجاع 100 دولار التي دفعها فقط وفي أحسن حالاته يمكن أن تنضاعف له إلى مرتين أو أكثر ولكنها حتما لاتستغرق الأسهم المدفوعة جميعا، فالرابحه الأكبر دائما هو صاحب محل القمار الذي لم يقدم شيئا إلآ أعمال النصب التي اكتسبها باسم القانون، أما صاحب النظام الكسرؤ وهو البنك فهو بأخذالأموال من زبائنه ويقرض عليها أضعافا 
مضاعفة بنسبة مثلا 4\% كما هي الحال في ماليزيا و10\% كماهي الحال في أمريكا وبفوائد مركبة، عل الاحتمال الراجه لديه أنّه لايمكن أن يستر جع كل الزبائن ما دفعوه مرة واحدة، فهذه الكسور العددية إنما تشير لتمليك شيء وهمي لصالح ذمّة مزيفة اكتسبت مصداقيتها وقوتا باسم القانون على حساب قوت المحرومين ومستقبل أبنائهم. والحقيقة أنّ القمار في نتائجها أقل ضررا من نطام البنك الكسري حيث إنّ الخسارة في القمار ونتائجها السلبية الإقتصادية والنفسية والاجتماعية والحنقية مقصورة غالبا على الزبائن المشاركين ودائرتم المحدودة أما في النظام الكسري البنكي فإنّ النتائج السلبية بكله أبعادها تتحملها الأغلية الساحقة من الشعوب المحرومة ونتائجها الكرثية كونيةٌ تتجاوز نطاق الدول والمنظمات وتتمدّد آثارها خلف أماكنها وأزماها فهي بجق أخطر على العالم من انفجار مافيه من قنابل نووية، وهل القنابل النووية وغيرها من الأسلحة الفتّاكة إلاّ أداة للقهر و والاستبداد بيد الأرباب الحقيقين للنظام الكسري البنكي لتثبيت سلطاهم والتفنّن في امتصاص الشعوب وتدجينها لصالح جشعهم وأنانيتهم، وخير شاهد على ذلك الأزمات المالية العالمبة وما نتج وينتج عنها من الحروب وفساد للإنسان والبيئة.

ومن خلال هذه الصفة القمارية التي توافرت جزئياتا في النظام الكسري يمكن أن ندرجه تحت حكم الآيتن

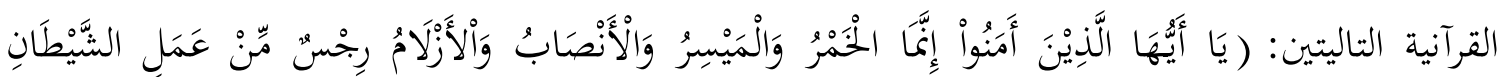

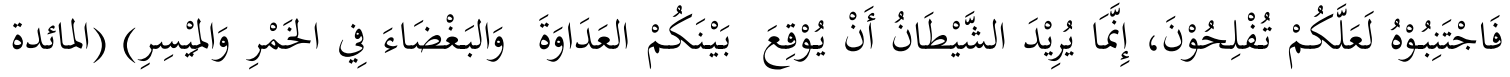
91-90) فهاتين الآيتين تبيّنان بوضوح شديد رجسيّة وشناعة هذا النظام الذي يعتمد في اختلاس أموال الشعوب وبحميعها على أسلوب المقمارة والمخاتلة، يقول النفسي في تفسيره لمعن الميسر الوارد في ها تين الآيتين" والميسر القمار مصدر من يسر كالوعد من فعله يقال يسرته إذا أقرمته، واشتقاقه من اليسر لأنه أخذ مال الرجل بيسر وسهولة بلا كد وتعب ، أومن اليسار كأنه سلب يساره ... وفي الميسر بارتقاق

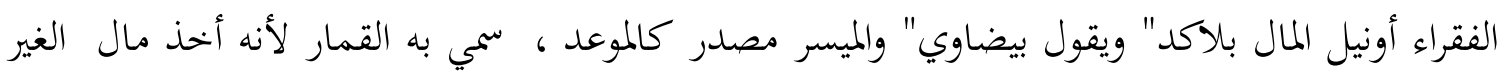
يسر أو سلب يساره".

فالقمار والنظام الكسري كلا هما بأخذ أموال الغير ويسلب يسارهم بخبث ومكروفق عملية واستراتيجيات معقّّدة يصعب التفطّن إليها أومعرفتها من من قبل البسطاء وعامة الناس. والداعاوى والتبريرات التي يطلقها المدفعون عن هذا النظام هي ذات الدعاوي التي يذرع بها المقامرون ، غير أنّ نتائجهما الشيطانية الواقعة على كلٌ المستويات الإقتصادية والسياسية والاجتماعية والأخلاقية تكشف تحافت هذه الدعاوي البراقة، "وأما الميسر ففيه بإزاء التوسعة على المحتاجين الأجحاف بأرباب الأموال، لأن من صار مغلوباً في القمار مرة دعاه ذلك إلى اللجاج فيه عن رجاء أنه ربما صار غالباً فيه ، وقد يتفق أن لا يكصل له ذلك إلى إلى ان لايبقى فقيرً مسكيناً ويصير من أعدى الأعداء لألكك الذين كانوا غالبين له فظهر من هذا الوجه أن لهن 
الخمر والميسر سببان عظيمان في إثارة العداوة والبغضاء بين الناس ، ولا شك أن شدة العداوة والبغضاء

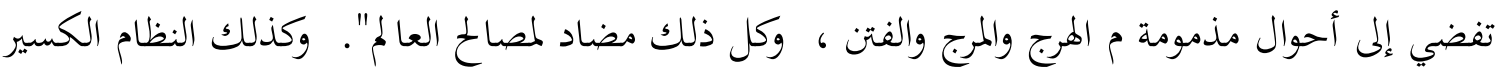

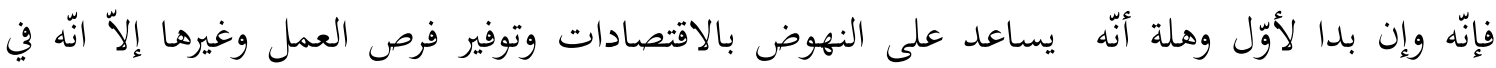

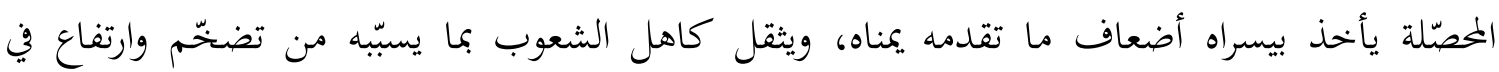

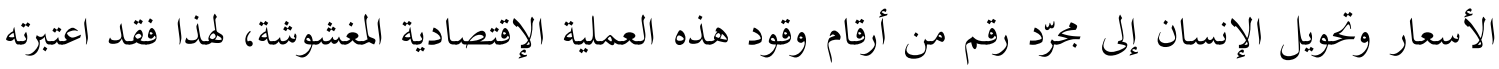
الآية رجساً من عمل الشيطان الذي يجب اجتنابه.

ثانيا : الصفة الربوبية، إنه لمن إجهاف حقا أن بنعل الزيادة التي يكصل عليها المرابي مقابل الأجل وبين

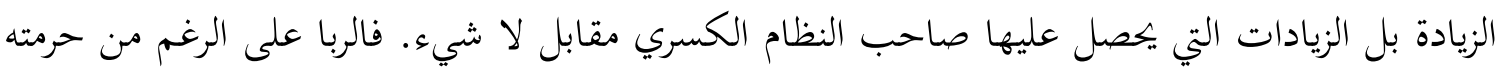

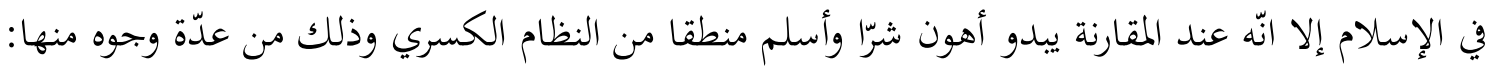
1. أن الزيادة التي يكصّلُ عليها من الربا هي مقابل لأجل أمّا الزيادة التي يحصّلَ عليها من النظام الكسري

$$
\text { هي مقابل للاً شيء. }
$$

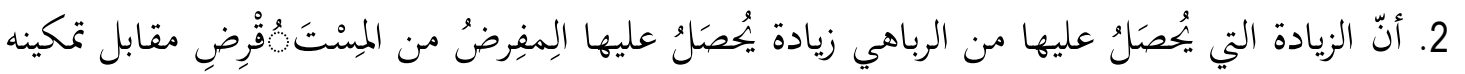

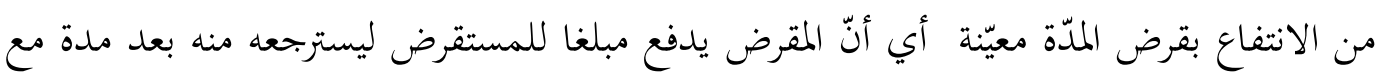

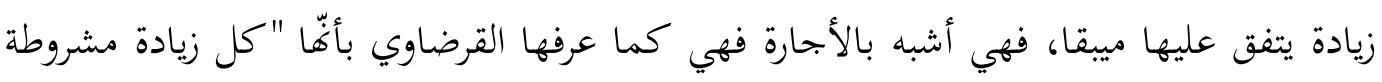

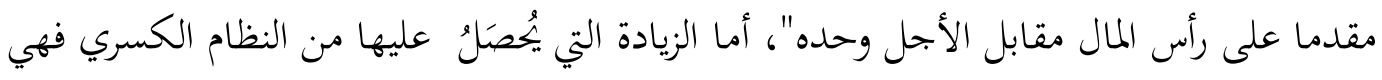

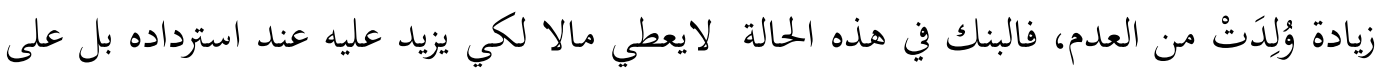

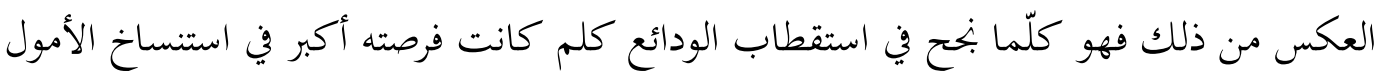

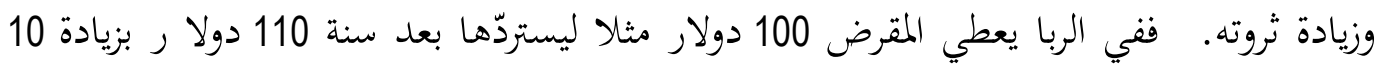

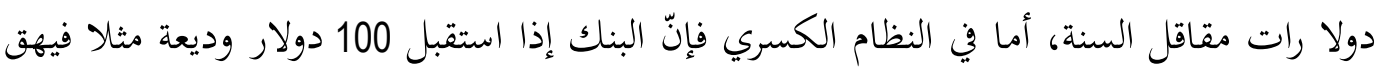

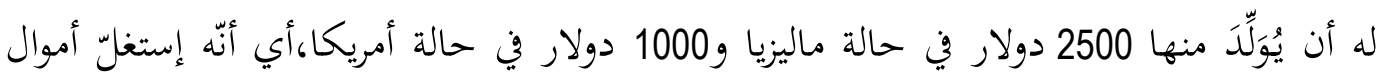

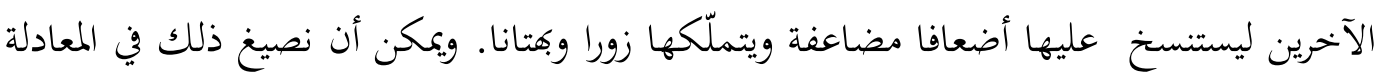

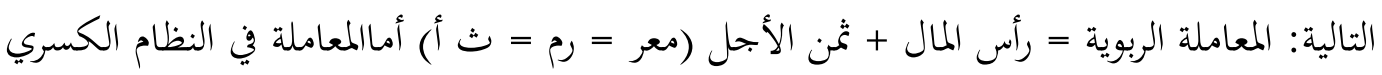

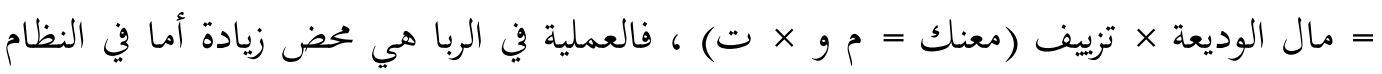

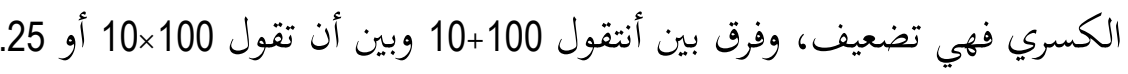

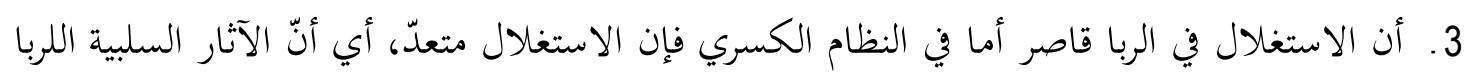

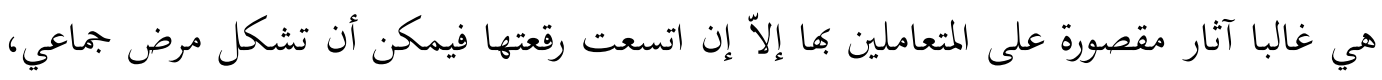

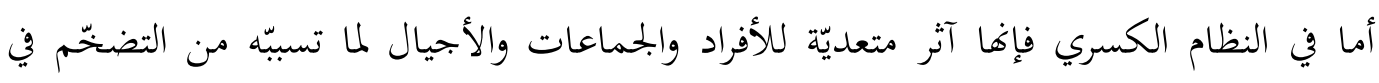


الإقتصاد وزيادة الأسعار من خلال إغراق السوق بالعملة المزيفة التي لامقابل لها في الإحتياط إلاّ جسع أصحابها وأنانيتهم. فالمجتمع كلّه هو الذي يتحمّل أعباء التعويض لهذا التضخم السرطاني

$$
\text { وآثاره السيئة. }
$$

4. أنّ كلا العمليتين تعتمد في التملّك على الربح المضمون وليس على قاعدة المال مقابل الجهد أو

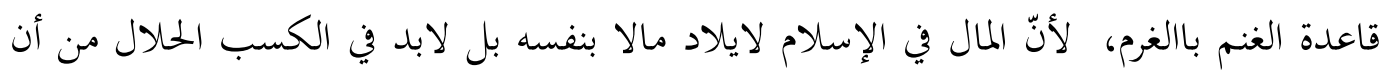
يكون ثمرة جهد يبذل أو ربحا من بحارة يتحمّل صاحبها تبعات احتمال الخسارة والربح على السواء أي أنّ الربح يكون "مقابل تحمل الخسارة في العقود الشرعية بشروطها التي تكفل تحقيق المصالح والموءمة بينها وتدفع المفاسد"

وبناء على ما تقدّم فإنّ النظام الكسري قد تضمّن العلل التي حرم من أجلها الرباوزيادة، أي أنّ استحقاق نعت النظام الكسري بالحرمة هومن باب الأولى، فا الخطاب الوارد في الآيات القرآنية بتحريم الربا يشمل الربا وما فوقه، قال تعالى: (يا أيهاالذين ءامنوا لا تأكلوا الربا أضعافا مضاعفة واتقوا الله لعلكم تفلحون والتقوا النار التي أعدت للكافرين) وقال أيضا: (الذين يأكلون الربا لايقومون إلا كما يقوم الذي يتخبه الشيطان من المس ذلك بأفم قالوا إنما البيع مثل الربا وأحل الله البيع وحرم الربا فمن جاءه موعظة من ربه فانتهى فله ما سلف وأمرا إلى الله ومن عاد فأولئك أصحاب النار هم فيها خالدون، يمحق الله الربا ويربي الصدقاة والله لايحب كل كفار أثيم... يا ايها الذين ءامنوا التقوا الله وذروا مابقي من الربا إن كنتم مؤمنين فإن لم تفعلوا فأذنوا بحرب من الله ورسوله)، وبما أنّ الآثار المترتبة عن التعامل با الظام الكسري هي أكثر شناعة وأعظم خطرا من الآثار المترتبة عن التامل باالربا فإنه يمكننا القول بأنّ النظام الكسري داخل في مفهوم هذه الآيات من طريقة التنبيه بالأدنى على الأعلى أي إذا كان الربا حراما كما هو مصرّح به في الآية فإن النظام الكسري يكون أولى بالتحريم و المنع من الربا. وإذ كان كل من شارك في العمليّة الربوّية آتم ملعون فإنّ كلّ من شارك في خلق هذه النظام وشرّع له هو ملعون كذلك من باب أولى، عن جابر رضي الله عنه قال: "لعن رسول الله صلى الله عليه وسلم آكل الربا وموكله وكاتبه وشاهدية وقال هم سواء".

الصفة الإثمية والباطلية: لو افترضنا جدلا أنّ سماسرة النظام الكسري استطاعوا من حلال بعد أجرائهم من موظفي ما يسمى بكيئات الرقابات الشرعية أن يشوّشوا على الاستنتاجات السابقة وأن يبرئوا إلى حين النظام الكسري من صفتي القمارية والربوية ويخرجوه من مدلولي الآيات السابقة فإنهم حتما لن يستطعوا أن ينفوا صفات القبح والباطل والظلم عن هذ النظام فضلا أعن أن يكون بمكدورهم أن يضفوا عليه صفات الحق والجمال والعدل، لأنّه لبي بمقدورهم بحاوز شهادات كثير من أهل الذكر من فطاحلة الإقصاد الذين شهدوا على قبح هذا النظام وجوره، فالعمدة والمرجع في هذه المسألة وفق الشريعة الإسلامية هم هؤلاء 


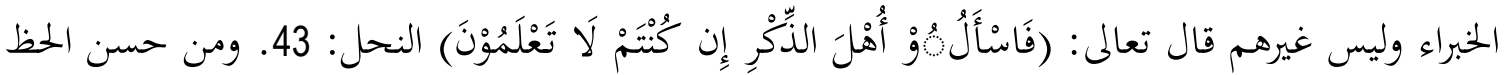

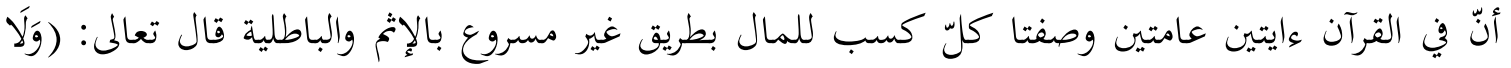

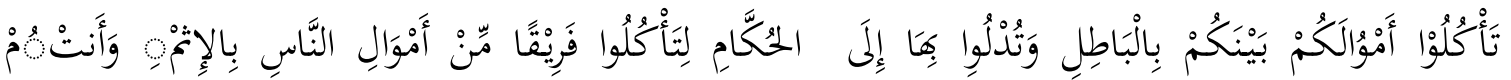

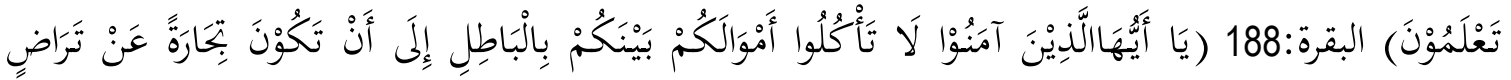

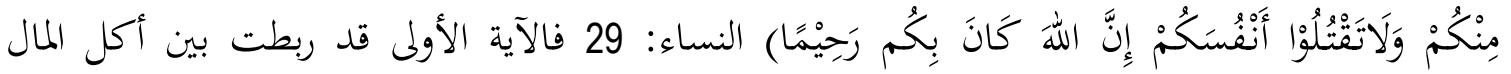

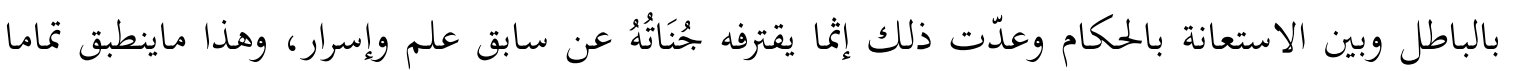

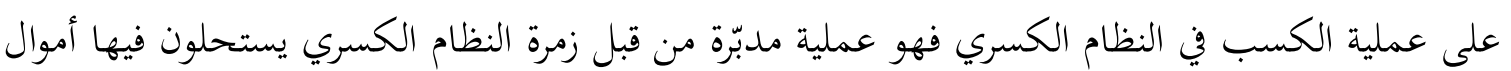

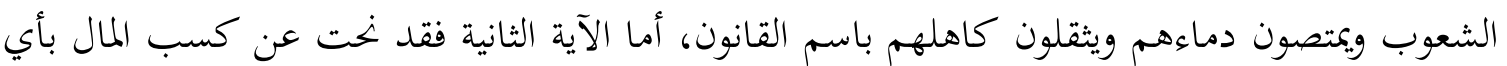

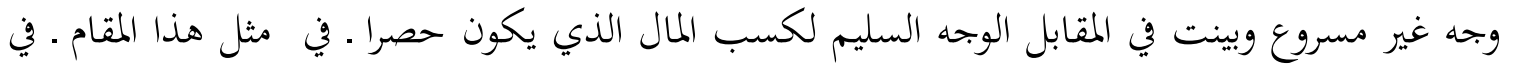

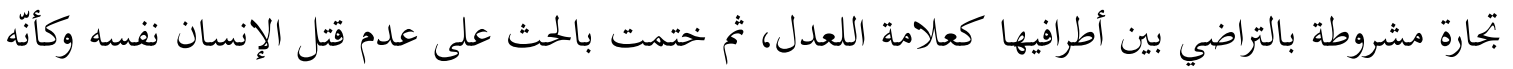
إشارة إلى أن أكل المال بالباطل يودّدي حتما إلى قتل الإنسان نفسه لما يسبّبه من استغلال وقطيعة وتحاسد

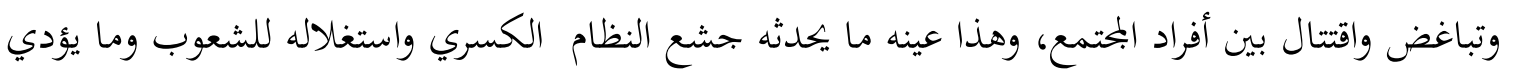

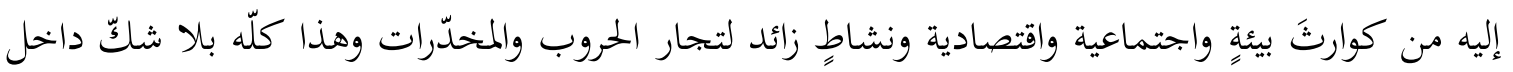
في مفهوم هاتين الآيتين ومؤكّد لإثمية هذا النظام وبطاليتّة.

والباطل يشمل كل معاملة لاتتوافق وأصول الشريعة كالتزييف والغشّ والتحايل وغيره من الوجوه المنحرفة، قال أبو حيان "والباطل هو كل طريق لم تبحة الشريعة، فيدخل فيه: السرقة، والخيانة ، والغصب، والقمار،

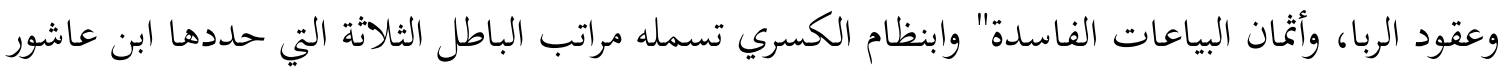

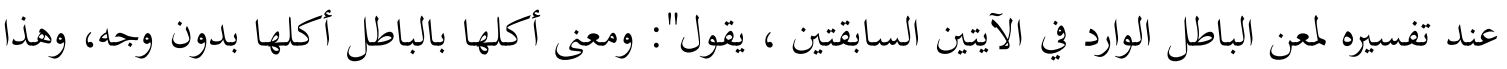

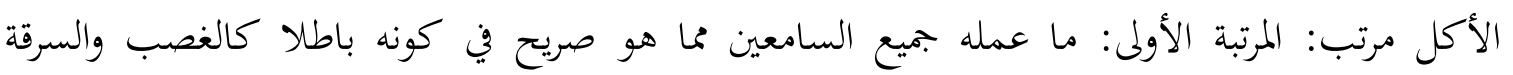

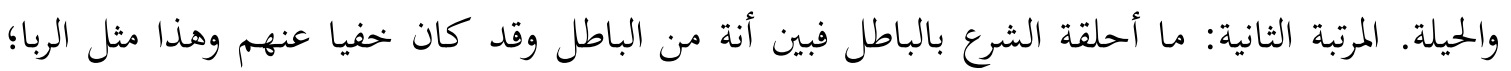

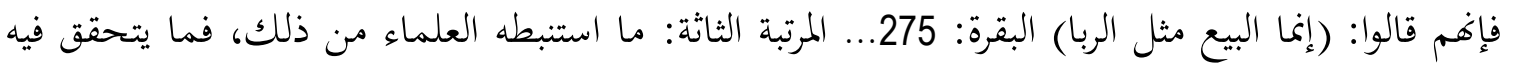

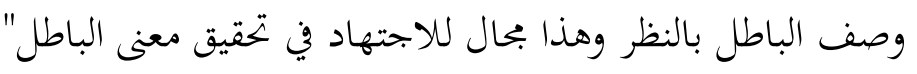

فعلى المرتبة الأولى فإنّّ النظام الكسري لاشك أنّ الطريقة التي يخلق به الأموال هي نوع من السرقة والحيلة،

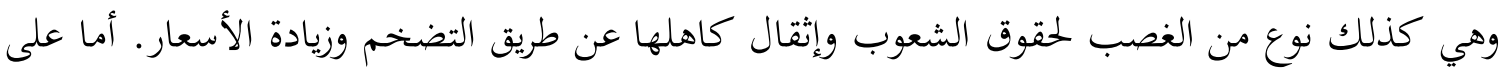

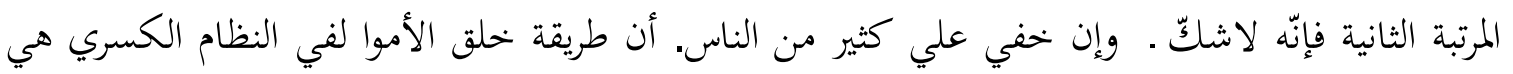

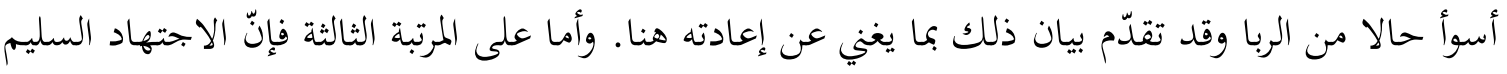

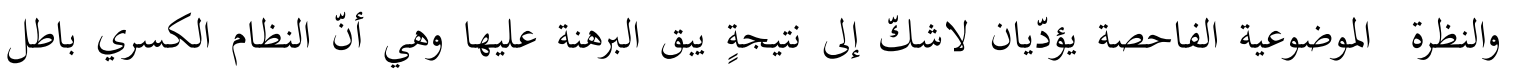




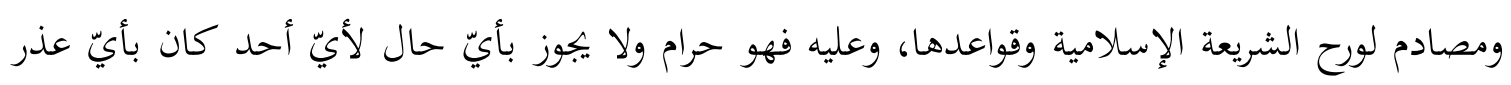

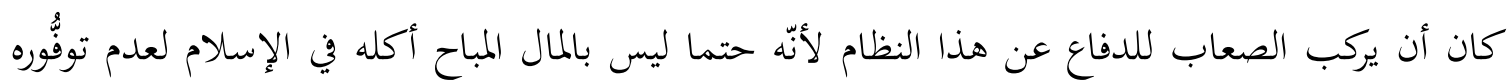

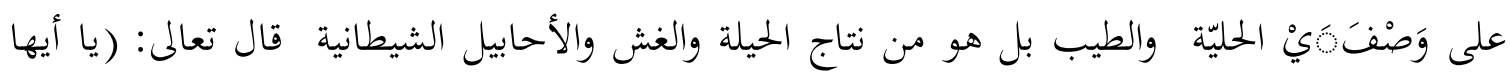

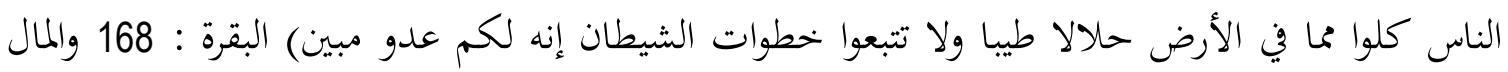

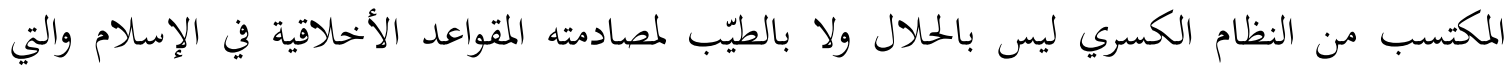

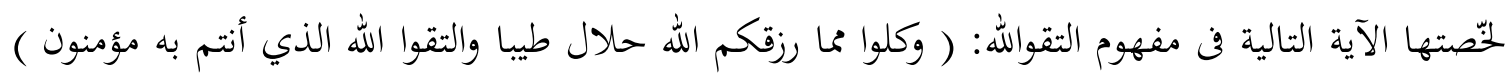

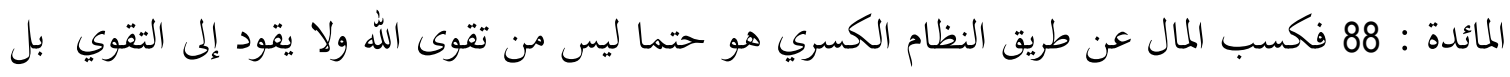
هو نوع من التخوّض والتموية والتحايل والغش في كسب المال الذي حرمته الشريعة الإسلامية قَالَ النَّبَّ

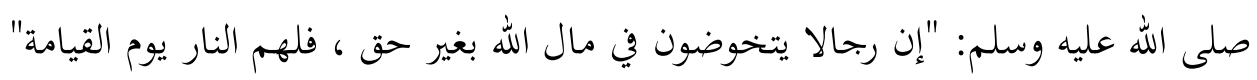




\section{المصادر والمراجع}

Larry Gonick and Woollcott Smith, The cartoo Guide to Statistics, New York: Harper Perennial, 1993.

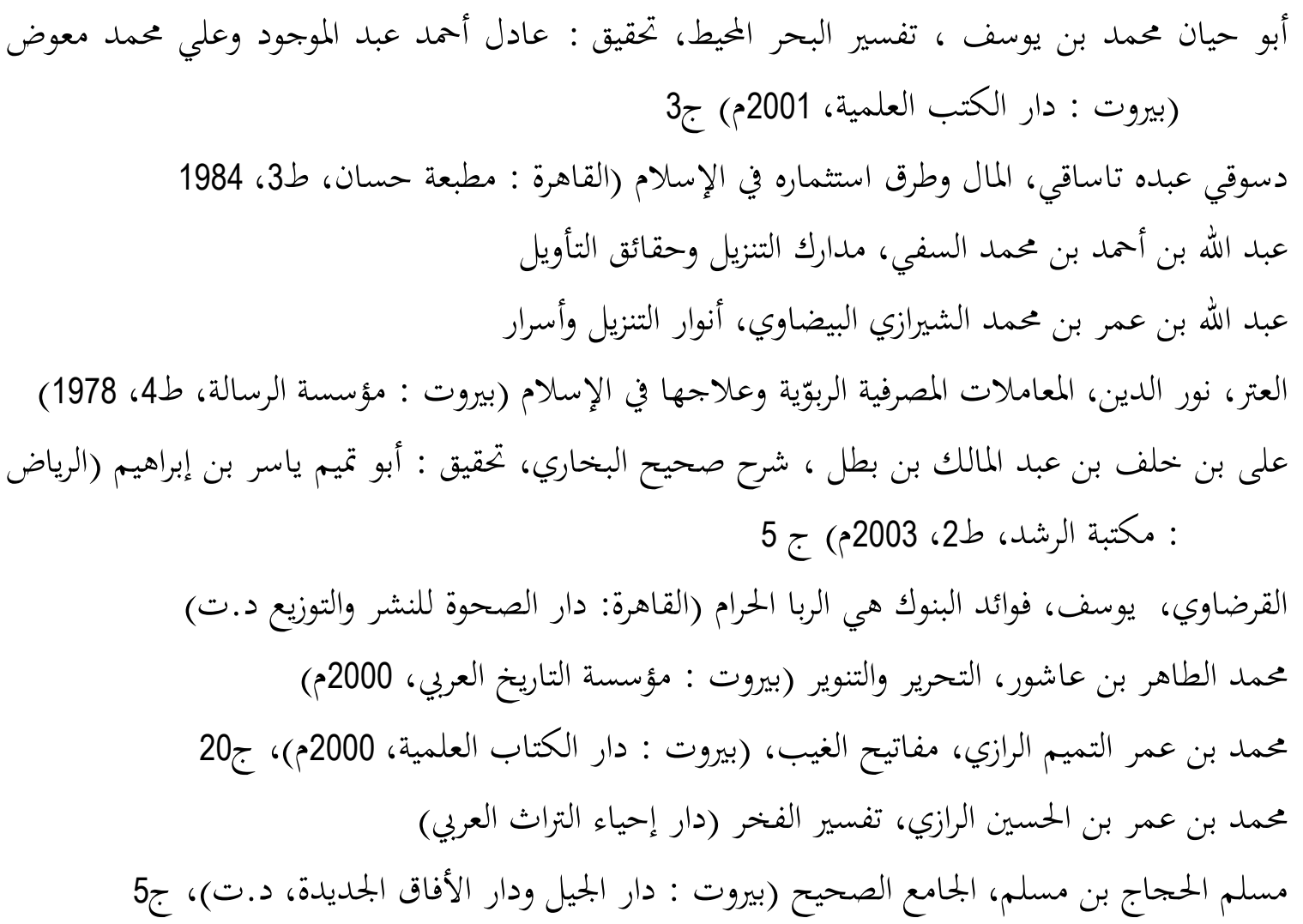

